\title{
O processo de ensino e aprendizagem dos alunos com TEA nas escolas regulares: uma revisão de teses e dissertações
}

\author{
MÁRCIA GORETT RIBEIRO GROSSI \\ Centro Federal de Educação Tecnológica de Minas Gerais (CEFET-MG), Belo Horizonte, MG, Brasil. \\ E-mail: marciagrossi@terra.com.br
}

VITOR GABRIEL RIBEIRO GROSSI

Universidade de São Paulo (USP), São Paulo, SP, Brasil.

E-mail: vitorgrossi@terra.com.br

BRENO HENRIQUE RIBEIRO GROSSI

Universidade Federal de Ouro Preto (UFOP), Ouro Preto, MG, Brasil.

E-mail: brenogrossibh99@gmail.com

\section{Resumo}

Este artigo teve como objetivo fazer uma revisão das dissertações de mestrado e teses de doutorado que analisaram o processo de ensino e aprendizagem de alunos com transtorno do espectro autista (TEA) nas escolas regulares. Assim, foi feita uma pesquisa documental, na qual se utilizaram documentos do banco de teses e dissertações do portal do Instituto Brasileiro de Informação em Ciência e Tecnologia (Ibict). O corpus do estudo foi composto de 772 pesquisas. Porém, após uma leitura preliminar, selecionaram-se 144 pesquisas para análise, visto que 419 não tinham foco no processo de ensino e aprendizagem em escolas regulares e 209 apareceram repetidas na busca, a qual foi realizada no final do primeiro semestre de 2019. Vale destacar que não houve um recorte de tempo. Os resultados revelaram que, embora a legislação pertinente ao tema tenha proporcionado algumas garantias e o número de alunos com TEA em escolas regulares tenha crescido, a inclusão e a aprendizagem desses alunos ainda não são uma realidade, pois incluir não significa apenas fazer a matrícula. A escola regular ainda tem muito a fazer, como a adaptação de suas estruturas físicas, mudanças nas suas ações pedagógicas, o uso de tecnologias assistivas e de métodos de intervenção e a inclusão dos currículos funcionais. Também é 
preciso investir na formação continuada dos docentes, pois a formação inicial não os tem preparado para lidar com alunos com TEA.

\section{Palavras-chave}

Transtorno do espectro autista. Alunos com TEA. Educação especial. Processo de ensino e aprendizagem. Inclusão.

\section{INTRODUÇÃO}

A educação especial tem estado presente em importantes debates e ganhou "ênfase no Brasil nos últimos 20 anos a partir de uma perspectiva de democratização dos espaços, acessos e respeito à diversidade" (SILVA; COSTA; GROSSI, 2017, p. 124), principalmente pelo destaque dado pela Lei $\mathrm{n}^{\circ} 12.764$, de 27 de dezembro de 2012, no seu art. 58 que "Entende-se por educação especial, para os efeitos desta Lei, a modalidade de educação escolar oferecida preferencialmente na rede regular de ensino, para educandos com deficiência, transtornos globais do desenvolvimento e altas habilidades ou superdotação" (BRASIL, 2012), desvinculando-a da proposta de uma educação para pessoas com deficiência que deva ser realizada apenas em escolas especiais.

Decorrente desse posicionamento governamental, percebe-se aumento no número de matrículas na educação especial, atingindo 1,2 milhão de alunos em 2018, conforme o Instituto Nacional de Estudos e Pesquisas Educacionais Anísio Teixeira (Inep), por meio do Censo Escolar de 2018. Ainda de acordo com o Inep, na educação especial, o percentual de matrículas de alunos incluídos em escola regular, na faixa etária entre 4 e 17 anos, também vem aumentando, passando de 87,1\% em 2014 para 92,1\% em 2018.

Vale esclarecer que fazem parte da educação especial os alunos com deficiências, transtornos globais do desenvolvimento e altas habilidades/superdotação. Entre esses, estão os alunos que apresentam o transtorno do espectro autista (TEA), foco deste estudo, que é um transtorno do desenvolvimento neurológico, apresentando três dimensões de comportamento: interação social recíproca; comunicação e linguagem; interesses restritos e comportamentos repetitivos e estereotipados, de acordo com o Diagnostic and statistical manual of mental disorders (DSM) na sua quinta versão.

As matrículas dos alunos com TEA acompanham a tendência de crescimento de matrículas da educação especial. De acordo com o Inep, o número de alunos com TEA matriculados em escolas regulares aumentou de 77.102 
(em 2017) para 105.842 (em 2018), representando um aumento de 37,28\% em apenas um ano. Porém, não existem dados que permitam avaliar a qualidade do atendimento desses alunos nas escolas regulares (TENENTE, 2017), as quais devem ser um espaço importante de encontro e potencializador para o aluno com autismo (PINTO, 2013).

Pensando nesse contexto, surgiu a questão que originou este estudo:

- A escola regular está pronta para receber em suas salas de aula o aluno com TEA?

Para responder a esse questionamento, este artigo teve como objetivo fazer uma revisão das dissertações de mestrado e teses de doutorado que analisaram o processo de ensino e aprendizagem de alunos com TEA nas escolas regulares.

Destaca-se a relevância social deste artigo, dada a importância da inclusão escolar de crianças e adolescentes com TEA, que é um conjunto de desordens do desenvolvimento neuropsíquico caracterizadas por déficits no comportamento social, como redução do contato visual e baixa expressividade facial. Outros sintomas motores, como estereotipias, também podem estar associados e estão presentes desde a infância, podendo limitar ou prejudicar o funcionamento diário do indivíduo (AMERICAN PSYCHIATRIC ASSOCIATION, 2014). Além do autismo propriamente dito, algumas entidades desse grupo se destacam por características relativamente específicas, como a síndrome de Rett (classificada pelo DSM-IV como um transtorno invasivo do desenvolvimento, sendo considerada uma das causas mais frequentes de deficiência múltipla severa com predominância em crianças do sexo feminino) e a de Asperger (transtorno neurobiológico colocado dentro da categoria transtornos do neurodesenvolvimento). Já no DSM, em sua quinta versão, publicada em 2013,

\section{[...] os quadros de Transtorno de Rett e o Transtorno Desintegrativo da Infância foram excluídos do âmbito do espectro do autismo. Os indivíduos que antes qualificavam para a condição de Asperger passaram a ser avaliados conforme $o$ critério mais abrangente de TEA (BONOTTO, 2016, p. 29).}

Bartoszeck e Grossi (2018) complementam os sintomas e as características dos indivíduos com TEA: fala monótona, sem variação de altura do som; rara gesticulação para enfatizar a expressão verbal; feição inexpressiva, sem variação facial quando fala; aprecia demasiadamente atividade rotineira ou 
repetitiva, como observar longamente água escorrendo da torneira, cheirar compulsivamente cada objeto; dificuldade em interpretar expressão facial do outro (falha na interação); hipersensibilidade ou falta de reação a sons e luminosidade (sirene de ambulância, luzes intensas atraem ou afugentam); obsessão em cheirar objetos, como lápis de cor antes de usar, cabelo da mãe, creme dental.

De acordo com o DSM-5, todos os indivíduos com TEA apresentam esses sintomas e características em intensidades diferentes. Embora já se conheça muito sobre esse transtorno, a ciência ainda não conseguiu determinar o que leva um indivíduo a nascer autista. O que se sabe é que existem indícios de que fatores genéticos desempenham um papel importante na etiologia do TEA. Não só a história familiar é um fator de risco, como as taxas de concordância entre gêmeos monozigóticos são muito maiores do que em gêmeos dizigóticos (PARK et al., 2016; HALLMAYER et al., 2011). Além disso, também já existem evidências de que fatores ambientais estejam implicados, como infecções neonatais, por exemplo: rubéola, uso materno de anticonvulsivantes, como o ácido valproico, ou de agentes teratogênicos, tais como a talidomida, doenças autoimunes e deficiência de zinco, entre outros. Acredita-se que os transtornos do referido espectro seriam multifatoriais, resultando de uma complexa interação de fatores ambientais e genéticos (PARK et al., 2016; EISSA et al., 2018).

No que se refere à fisiopatologia, Bartoszeck e Grossi (2018) afirmam que existem indícios de alterações no córtex cerebral nos indivíduos com TEA, além de prejuízos em outras áreas do encéfalo, como amígdala, núcleo accumbens e sistema límbico. Este último participa na regulação dos comportamentos instintivos e emocionais, indicando relevância para a neuropatologia do autismo. E são muitas as crianças que apresentam o TEA. Segundo dados da Organização das Nações Unidas (ONU), em 2014, cerca de 1\% da população mundial apresentava TEA, sendo aproximadamente um caso para cada 68 crianças. De acordo com o seu secretário-geral, Ban Ki-moon, rejeitar pessoas com autismo "é uma violação dos direitos humanos e um desperdício de potencial humano" (ORGANIZAÇÃO DAS NAÇÕES UNIDAS, 2016). Por isso a preocupação com a aprendizagem dos alunos com TEA.

No Brasil, o direito à educação é assegurado por meio da Constituição Federal de 1988, a qual apresenta destaque para a educação de pessoas com necessidades especiais, no artigo 208 e inciso III, com a seguinte redação: "Atendimento educacional especializado aos portadores de deficiência, preferencialmente na rede regular de ensino". A partir de então, as legislações co- 
meçam a estabelecer disposições que fazem com que a educação das pessoas com deficiência seja vista como uma educação de caráter inclusivo, como a LBDN n ${ }^{\circ} 9.394$ de 20 de dezembro de 1996.

De acordo com Castanha (2016, p. 52), "em 1999, o Brasil deu passos significativos em âmbito legal para avançar no processo de inclusão" com a criação do Conselho Nacional dos Direitos da Pessoa com Deficiência (Conade), por meio do Decreto $\mathrm{n}^{\circ} 3.076$, de $1^{\circ}$ de junho de 1999 , o qual foi revogado pelo Decreto $\mathrm{n}^{\circ} 3.298$, de 20 de dezembro de 1999, que dispôs sobre uma nova Política Nacional para a Integração da Pessoa Portadora de Deficiência. Em relação especificamente ao autismo, a iniciativa governamental que representou um marco histórico foi a Lei $\mathrm{n}^{\circ} 12.764$, de 27 de dezembro de 2012, que instituiu a Política Nacional de Proteção dos Direitos da Pessoa com TEA. Entre outros pontos, essa lei determina que os autistas possam frequentar escolas regulares e, se necessário, solicitar acompanhamento nesses locais.

Esses incentivos legais foram responsáveis pelo aumento da presença de alunos com TEA na escola regular, o que, por si só, não significa inclusão. Incluir está associado também com a permanência e a aprendizagem do aluno. Portanto, percebe-se a necessidade de desenvolver estratégias interventivas que favoreçam a aprendizagem desses alunos (MACÊDO, 2015). Para tal, os professores precisam estar preparados para lidar com alunos com TEA, "proporcionando através de estratégias pedagógicas específicas a Educação Inclusiva para a promoção do desenvolvimento dos alunos autistas, que embora apresentem determinados distúrbios, são capazes de desenvolver muitas habilidades" (BARTOSZECK; GROSSI, 2018, p. 50). Entretanto, Bartoszeck e Grossi (2018) realizaram uma pesquisa em 2016 com 1.076 matrizes curriculares de cursos de Pedagogia, Normal superior e nos Programas Especiais de Formação Pedagógica de docentes, todos cadastrados no portal e-MEC de todo o país, procurando disciplinas sobre o autismo. A pesquisa mostrou que só $0,56 \%$ aborda a questão em suas matrizes curriculares.

Em outra pesquisa, realizada por Grossi, Lopes e Couto (2014), sobre a formação docente, com o objetivo de verificar se estes estavam sendo formados com conhecimentos sobre o funcionamento do cérebro, verificou-se que, em um universo de 352 instituições, apenas 6,25\% contemplavam as disciplinas de neurociência e correlatas nas suas matrizes curriculares. Essa pesquisa foi repetida após cinco anos e verificou que pouco se alterou. Da segunda vez, foram analisadas 1.317 instituições e só 7,9\% contemplavam as disciplinas de neurociência e correlatas nas suas matrizes curriculares (GROSSI; OLIVEIRA; 
AGUIAR, 2019). Trata-se de dados preocupantes, já que os professores estão se formando com pouco conhecimento sobre o funcionamento do cérebro, pouco conhecimento acerca da educação especial e especificamente sobre o TEA. Essa precariedade da formação docente para lidar com o aluno com esse transtorno é um dos desafios a ser superado para garantir o sucesso desse aluno na escola regular (PEREIRA, 2014). Para Pereira (2014, p. 36), "a chegada do aluno com autismo questiona a formação docente".

Dentro dessa questão, destaca-se também a formação dos professores no que se refere ao uso das tecnologias assistivas (TA), as quais "levam em seu bojo a subárea da Comunicação Aumentativa e Alternativa (CAA), visam à autonomia e participação plena por meio da concepção, desenvolvimento, produção e distribuição de assistência e apoios" (BONOTTO, 2016, p. 16). Ainda de acordo com Bonotto (2016, p. 19), a "CAA, em especial, é um tipo de tecnologia que colabora para a eliminação das barreiras de comunicação interpessoal e as barreiras de acesso à informação e comunicação". Outro aspecto importante para a inclusão dos alunos autistas que deveria ser de conhecimento dos professores é o uso de recursos como o Sistema de Comunicação por Troca de Figuras (Pictures Exchange Communication System - PECS), que é um sistema de comunicação para pessoas com TEA, que integra um conjunto de possibilidades da CAA. Além disso, faz-se importante o uso dos métodos de intervenção para possibilitar o desenvolvimento social e cognitivo do aluno autista, como o Treatment and Education of Autistic and Related (TEACCH), que é um programa estruturado que combina diferentes materiais visuais para organizar o ambiente físico por meio de rotinas e atividades de trabalho, de forma a tornar o ambiente mais compreensível e ajudar na independência do aluno.

Soma-se a isso a elaboração do currículo funcional (FERNANDES, 2016), uma proposta de ensino que visa à melhoria da qualidade de vida dos alunos da educação especial, apontando caminhos, levando em consideração aspectos importantes para seu processo de inclusão, bem como do Plano Educacional Individualizado (PEI). Assim, não existe dúvida de que esses métodos de intervenção conjugados com as TA proporcionarão ricas atividades específicas para os alunos com TEA. Enfim, para incluir esses alunos na sala de aula, é preciso realizar atividades que favoreçam o convívio de forma ampla com todos os alunos, é preciso que a escola se transforme "por meio da formação de redes de apoio, com bom embasamento teórico" (PAULI, 2018, p. 10). É com esse enfoque que Neves (2018, p. 39) menciona o seguinte: 
Todos os alunos têm possibilidades de aprender e os profissionais mais experientes deverão ensinar de formas diferenciadas, conhecendo e explorando cada limitação. Os recursos utilizados pelo professor podem possibilitar a acessibilidade daquela criança com deficiência para a realização da sua verdadeira inclusão, interação social e desenvolvimento.

Para entender as possibilidades de aprendizagem dos alunos, é preciso compreender como o cérebro aprende. Isso ajuda na escolha das atividades pedagógicas que estimulam as sinapses e consolidam o conhecimento ((BARTOSZECK; GROSSI, 2018). Isso é válido para todos alunos, especialmente os que possuem algum tipo de deficiência. Assim, com base nessas considerações, elaborou-se o Quadro 1, que apresenta, a título de contribuição para a educação dos alunos com TEA, as estratégias pedagógicas convencionais, os métodos de intervenções e as TA dialogando com a neurociência.

Quadro 1 Princípios da neurociência e as práticas pedagógicas a serem usadas para o ensino com alunos com TEA

\begin{tabular}{|c|c|c|}
\hline $\begin{array}{l}\text { Princípios de } \\
\text { neurociência }\end{array}$ & $\begin{array}{l}\text { Estratégias pedagógicas } \\
\text { convencionais }\end{array}$ & $\begin{array}{c}\text { Complemento como atividade/apoio } \\
\text { desenvolvido especificamente } \\
\text { para autistas }\end{array}$ \\
\hline $\begin{array}{l}\text { 1. O cérebro mostra } \\
\text { janelas de } \\
\text { oportunidade, os } \\
\text { períodos } \\
\text { sensíveis, para } \\
\text { aprendizagem. }\end{array}$ & $\begin{array}{l}\text { - Apresentação da rotina } \\
\text { educacional } \\
\text { antecipadamente, } \\
\text { permitindo modulação } \\
\text { sensorial e autorregulação } \\
\text { emocional. } \\
\text { - Resolução de problemas e } \\
\text { o aprendizado por meio da } \\
\text { experiência. } \\
\text { - Uso de cartaz com palavra } \\
\text { e desenho ao lado, o } \\
\text { professor lê e a criança } \\
\text { repete. Uso de livro com } \\
\text { ilustrações e CD com fala/ } \\
\text { canções. } \\
\text { - Uso do sintetizador de fala. } \\
\text { - Uso de diversos materiais } \\
\text { sensoriais. }\end{array}$ & $\begin{array}{l}\text { - Tecnologias assistivas, como o } \\
\text { software GRID2, para ajudar na } \\
\text { comunicação de forma autônoma. } \\
\text { - Tecnologias assistivas, como o recurso } \\
\text { Sistema de Comunicação Alternativa } \\
\text { para Letramento de Sujeitos com } \\
\text { Autismo (Scala), para incentivo da } \\
\text { oralidade nos déficits de comunicação. } \\
\text { - Método de intervenção, como o } \\
\text { TEACCH, atuando no ambiente para } \\
\text { evitar comportamentos indesejados } \\
\text { e conseguir o uso da linguagem } \\
\text { expressiva e receptiva. } \\
\text { - Sistema de Comunicação por Troca } \\
\text { de Figuras (PECS) para ajudar no } \\
\text { desenvolvimento das habilidades } \\
\text { sociais e de iniciação da } \\
\text { comunicação. }\end{array}$ \\
\hline
\end{tabular}




\section{Princípios de neurociência}

\section{Estratégias pedagógicas convencionais}

\section{Complemento como atividade/apoio desenvolvido especificamente para autistas}

2. O cérebro se modifica aos poucos estruturalmente como resultado da experiência motora.
- Montagem de brinquedos de madeira, Lego, quebra-cabeça, bordar em telas com desenho pré-pronto, modelar massinha colorida, modelar com argila.
3. O cérebro mostra neuroplasticidade (sinaptogênese) aumentando a densidade sináptica, por exemplo, alfabetização em ciências, biologia.
- Uso de mapa mental com recorte e colagem de gravuras, plastificar folhas de árvores, penas de pássaros, asas de borboletas.

- Visita ao zoológico, Museu de História Natural (jardim das sensações).
- Análise do comportamento aplicada por meio do ensino de novas habilidades, instigando a criatividade e propondo atividades novas para o aluno.
- Análise do comportamento aplicada, ajudando o aluno a executar tarefas ou relações sociais.

- Método de intervenção como o TEACCH, por meio do uso de estímulos visuais, corporais e audiocinestesicovisuais para complementar a comunicação verbal.
4. Ativação simultânea de inúmeras áreas do córtex cerebral durante nova experiência de aprendizagem.
- Criar situações que reflitam o contexto da vida cotidiana, uma vez que a informação nova se ancora no conjunto da compreensão anterior, como identificar objetos pelo tato, tais como prato e colher de plástico.
- Análise do comportamento aplicada, ajudando o aluno a executar tarefas ou relações sociais.

- Sistema de comunicação PECS, para ajudar no desenvolvimento das habilidades sociais e de iniciação da comunicação.

\section{O cérebro foi} concebido evolutivamente para perceber as gravuras, as imagens e os sons registrados na memória e responder a eles.
- Uso de práticas que explorem execução de desenhos, identificação de categorias nas gravuras (animais, plantas, ferramentas, artigos de cozinha, roupas, calçados).

- Cantar músicas populares, cantigas de roda, declamar poesia.
- Tecnologias assistivas, como o recurso Scala na produção de narrativas.

- Método de intervenção TEACCH, por meio do uso de informação visual e escrita para complementar a comunicação verbal, bem como a aplicação da metodologia das atividades de vida diária (AVD) para fornecer ao aluno maior independência. 
Quadro 1 Princípios da neurociência e as práticas pedagógicas a serem usadas para o ensino com alunos com TEA (continuação)

\begin{tabular}{|c|c|c|}
\hline $\begin{array}{l}\text { Princípios de } \\
\text { neurociência }\end{array}$ & $\begin{array}{l}\text { Estratégias pedagógicas } \\
\text { convencionais }\end{array}$ & $\begin{array}{c}\text { Complemento como atividade/apoio } \\
\text { desenvolvido especificamente } \\
\text { para autistas }\end{array}$ \\
\hline $\begin{array}{l}\text { 6. Ações de } \\
\text { aprendizagem, } \\
\text { memória e } \\
\text { emoções, se } \\
\text { ativadas } \\
\text { simultaneamente, } \\
\text { ficam interligadas } \\
\text { pelo processo } \\
\text { educacional. }\end{array}$ & $\begin{array}{l}\text { - Proporcionar um ambiente } \\
\text { que seja calmo para } \\
\text { encorajar o aluno a } \\
\text { desenvolver criatividade e } \\
\text { resolver problemas. } \\
\text { - Uso de computadores para } \\
\text { a prática da digitalização } \\
\text { de texto e sintetizador de } \\
\text { fala. } \\
\text { - Fazer atividade em } \\
\text { pequenos grupos. }\end{array}$ & $\begin{array}{l}\text { - Tecnologias assistivas, como o uso } \\
\text { do software GRID2. } \\
\text { - Tecnologias assistivas, como o } \\
\text { recurso Scala na produção de } \\
\text { narrativas. } \\
\text { - Análise do comportamento aplicada, } \\
\text { para restringir comportamentos: } \\
\text { trabalhar o ambiente para torná-lo } \\
\text { mais agradável. } \\
\text { - Métodos de intervenção, como o } \\
\text { TEACCH, como suporte estruturado } \\
\text { para a comunicação social. }\end{array}$ \\
\hline
\end{tabular}

Fonte: Adaptado de Bartoszeck e Grossi (2018).

Com base nas informações do Quadro 1, pode-se afirmar que as práticas pedagógicas, em que se utiliza uma combinação de estratégias pedagógicas convencionais com as TA e os diferentes métodos de intervenção, poderão contribuir para a inclusão dos alunos com TEA, de modo a potencializar o desenvolvimento social e a linguagem, e favorecer a aprendizagem escolar. Vale ressaltar que, antes de tudo, é necessária a inserção de estímulos sensoriais gradativamente, proporcionando adaptação ambiental e organização comportamental ao estímulo-resposta, e que o planejamento do que acontece na sala de aula depende do objetivo curricular, da forma como o aluno participa e como este é observado pelo seu professor, o qual deve interpretar as respostas e os comportamentos dos alunos.

Contudo, não existirão estratégias pedagógicas perfeitas se o professor não estiver envolvido e preparado para receber esses alunos com afetividade. O olhar do professor deve ter como foco o aluno e não somente a condição dele. Está no conhecimento e na dedicação do professor parte da solução para a inclusão dos alunos, que não podem ser segregados, uma vez que "não se deve acolher o autismo como uma patologia incapacitante, mas como uma maneira singular e inventiva de ser no mundo" (VIANA, 2015, p. 5). Pauli (2018, p. 130) reforça esse entendimento ao afirmar que "o potencial humano 
da escola, seus professores, orientadores, diretores e famílias, aliados à abordagem pedagógica adotada pela instituição, são o que produzem uma escola inclusiva ou não".

\section{MÉTODOS}

Neste estudo de caráter descritivo, adotou-se a pesquisa documental, na qual foram utilizados os documentos cadastrados no banco de teses e dissertações do portal do Instituto Brasileiro de Informação em Ciência e Tecnologia (Ibict). O critério para a busca dessas publicações se justifica pelo objetivo do artigo, que foi fazer uma revisão nas produções de pesquisas apresentadas nos programas de pós-graduação em nível de mestrado e doutorado, no Brasil, sobre o processo de ensino e aprendizagem de alunos com TEA nas escolas regulares.

O corpus do estudo foi composto de 772 pesquisas (dissertações de mestrado e teses de doutorado), as quais foram selecionadas a partir de uma busca no portal usando nove descritores: educação e autismo; educação, autismo e neurociências; sala de aula, autismo e neurociências; sala de aula e autismo; processo de ensino e aprendizagem e autismo; processo de ensino e aprendizagem e autismo e neurociências; ensino e autismo e neurociências; ensino e autismo; TEA e educação. Vale ressaltar que essa busca foi realizada no final do primeiro semestre de 2019 e não houve um recorte de tempo.

Após a leitura preliminar dos títulos, dos resumos, das palavras-chave e, em alguns casos necessários, do texto completo, verificou-se que, dentre as 772 pesquisas, várias não foram selecionadas para a análise. A seguir, apresentam-se os critérios de exclusão:

- Obtiveram-se 419 pesquisas (dissertações e teses) sobre autismo, mas que não foram desenvolvidas em escolas regulares e, sim, em instituições de atendimento educacional especializado (AEE) e/ou cujo foco não era o processo de ensino e aprendizagem.

- Na busca, 209 (dissertações e teses) aparecem repetidas.

Assim, o número real de pesquisas selecionadas para análise foi 144, representando 18,65\% do corpus do estudo. Em seguida, realizaram-se a leitura e o fichamento das 144 pesquisas, discriminando as seguintes categorias: tipo de trabalho (dissertação ou tese), o ano de defesa, região geográfica na qual a tese/dissertação foi desenvolvida; número de publicações por dependência 
administrativa; palavras-chave de cada trabalho; objetivo da pesquisa; a metodologia utilizada; a etapa escolar e o gênero dos alunos com TEA, e os principais resultados encontrados.

\section{RESULTADOS}

Após a análise das 144 pesquisas, obtiveram-se os resultados descritos a seguir.

\section{Tipo e quantidade de publicações por ano}

Verificou-se que $77,77 \%$ das pesquisas eram dissertações de mestrado, e $32 \%$, teses de doutorado. A educação inclusiva, a educação especial e especialmente o TEA são temáticas discutidas muito recentemente e ainda são campo de muitas controvérsias, necessitando de maiores estudos (NEVES, 2018, p. 10), o que pode ser observado pelos dados do Gráfico 1.

\begin{tabular}{c|l} 
Gráfico 1 & Quantidade de dissertações e teses publicadas sobre processo de ensino \\
e aprendizagem e alunos com TEA em escolas regulares
\end{tabular}

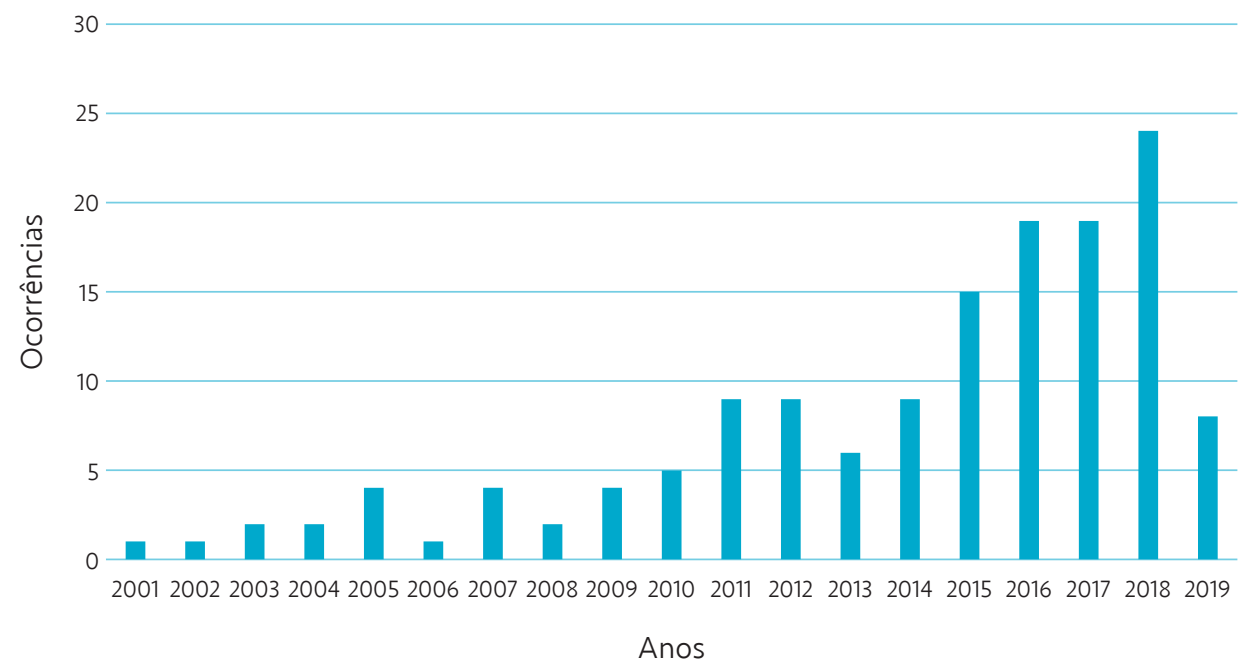

Fonte: Elaborado pelos autores.

Percebe-se que as primeiras pesquisas de mestrado e doutorado envolvendo a temática tiveram início em 2001, o que mostra que a preocupação com o tema é relativamente nova e pode estar relacionada ao fato de que foi na década de 1990 que houve uma ampliação das garantias legais para a educa- 
ção das pessoas com algum tipo de deficiência, como a Lei n ${ }^{\circ}$ 9.394/1996 capítulo V, que estabelece sobre a educação especial - e a Lei $\mathrm{n}^{\circ} 12.764 / 2012$ (CASTANHA, 2016).

Nota-se que o interesse pelas pesquisas sobre o tema tem se mostrado crescente no decorrer dos anos, mas com algumas oscilações (Gráfico 1). Observa-se também um decréscimo em 2019 que pode estar relacionado ao fato de que a presente pesquisa foi desenvolvida antes do final de 2019. Supõe-se que no início de 2020 o número de pesquisas referentes a 2019 poderá será maior que as de 2018 (ano que teve mais dissertações e teses publicadas, com 16,7\% dessas), quando as pesquisas feitas em 2019 já estarão digitalizadas e incorporadas no portal do Ibict. Então, espera-se que teremos mais pesquisas contribuindo para a compreensão do TEA e da inclusão dos alunos com esse transtorno nas escolas regulares. Conforme Castanha (2016, p. 12) alerta, a questão do autismo é um "problema muito sério, que infelizmente vem crescendo a cada ano". Portanto, faz-se necessário o desenvolvimento de pesquisas para dar visibilidade à questão, mostrando as barreiras e as possibilidades na educação de alunos com TEA.

\section{As palavras-chave das 144 pesquisas}

As palavras-chave são um importante instrumento que ajuda indexadores e mecanismos de busca a encontrar os estudos relevantes de uma área, já que seu uso "potencia o acesso ao conteúdo dos documentos, para além da informação que é representada pelo título e resumo; traduz o pensamento dos autores" (MIGUÉIS et al., 2013, p. 115). Nessa perspectiva, decidiu-se conhecer as palavras-chave das 144 dissertações e teses, com o intuito de verificar quais foram os enfoques e as particularidades dados pelos pesquisadores aos seus estudos.

O resultado foi a presença de 183 palavras-chave diferentes. Dentre essas, a mais frequente foi autismo, com recorrência de 97 vezes. Em seguida, em ordem decrescente de recorrência, as palavras-chave mais frequentes foram educação (70), espectro autista/TEA (49), inclusão (47), especial (26), comunicação (17), professores (16), transtornos (15), psicanálise (5), deficiência (4) e desenvolvimento infantil (3).

A presença em destaque das palavras autismo, educação e espectro autista/ TEA já era esperada como as que teriam maior frequência por causa do tema pesquisado. O que chamou a atenção foi a quarta palavra com maior destaque: inclusão. Esse fato foi compreendido na leitura das 144 pesquisas, as quais 
comprovaram a preocupação dos professores de alunos com TEA em acolhê-los nos ambientes escolares, pois, como foi observado nas pesquisas, a inclusão escolar das pessoas com deficiência ainda não é uma realidade, aproximando-se mais da segregação (CASTANHA, 2016).

\section{Áreas de conhecimento que têm pesquisado sobre o assunto}

As discussões teóricas passaram por 11 áreas do conhecimento, o que revela o interesse da temática em vários segmentos na sociedade e demonstra uma preocupação com a questão da inclusão de alunos com autismo nas escolas regulares. Como na busca feita os descritores eram termos que envolviam ensino, a maioria das pesquisas encontradas $(66,66 \%)$ foi desenvolvida na área da educação (Tabela 1).

Tabela 1 Número de publicações por área do conhecimento

\begin{tabular}{cc}
\hline Áreas do conhecimento & Número de publicações \\
\hline Educação & 96 \\
\hline Psicologia & 25 \\
\hline Matemática & 6 \\
\hline Linguística e Letras Aplicada & 5 \\
\hline Educação Física & 4 \\
\hline Ensino de Ciências & 2 \\
\hline Psicanálise & 2 \\
\hline Filosofia & 1 \\
\hline Engenharia & 1 \\
\hline Medicina & 1 \\
\hline Políticas Públicas & 1 \\
\hline
\end{tabular}

Fonte: Elaborada pelos autores.

\section{Região geográfica na qual a tese/dissertação foi desenvolvida}

Verificou-se que as universidades localizadas na Região Sudeste foram as que mais publicaram sobre o tema estudado (52,09\%). Em seguida, aparecem o Sul $(27,78 \%)$ e o Nordeste $(11,11 \%)$. Já a Região Centro-Oeste contribuiu 
com 6,94\% das pesquisas, e a Região Norte, com 2,08\%. Esse resultado pode estar relacionado com o fato de que os estados brasileiros que possuem o maior número de programas de pós-graduação stricto sensu estão localizados nas regiões Sul e Sudeste, como informado pelo Sistema de Informações Georreferenciadas (GeoCapes) da Coordenação de Aperfeiçoamento de Pessoal de Nível Superior (Capes).

\section{Número de publicações por dependência administrativa}

Verificou-se que a maioria das pesquisas foi desenvolvida em instituições federais $(56,95 \%)$, seguidas pelas instituições estaduais $(25,69 \%)$ e, por último, pelas instituições particulares (17,36\%). Dessa forma, $82,64 \%$ das pesquisas brasileiras envolvendo o processo de ensino e aprendizagem de alunos com TEA em escolas regulares foram desenvolvidas em instituições públicas. Esse resultado pode ser um indício de que os professores doutores e com regime de trabalho de dedicação exclusiva estão, principalmente, lotados nas instituições públicas, permitindo-lhes um investimento em pesquisas.

\section{Aspectos metodológicos utilizados nas pesquisas}

Quanto à natureza das pesquisas, 139 adotaram a abordagem qualitativa e cinco optaram pela abordagem quantitativa. Esse resultado já era esperado por conta das diferenças dessas abordagens, principalmente no que se refere "à interação dinâmica entre o pesquisador e o objeto de estudo. No caso da pesquisa quantitativa, dificilmente se escuta o participante após a coleta de dados" (GÜNTHER, 2006, p. 203), o que não ocorre na qualitativa. Ademais, Günther (2006, p. 203) apresenta outra distinção entre essas pesquisas: "é o de estudar um determinado fenômeno no seu contexto natural versus estudá-lo no laboratório". Nas 139 pesquisas, o fenômeno foi estudado nas escolas regulares (no contexto natural) e houve a escuta dos participantes após a coleta de dados.

Sobre os objetivos, a maioria das dissertações e teses foi do tipo exploratório (58\%), o que pode ser explicado pelo fato de que elas buscaram proporcionar maior familiaridade com os seus problemas de pesquisas, a fim de torná-los mais explícitos. Já 10,5\% das pesquisas foram descritivas e 31,5\%, etnográficas. Além disso, o tipo de pesquisa exploratória geralmente assume a forma de pesquisa bibliográfica e estudo de caso, que foram os principais procedimentos técnicos utilizados nas 144 pesquisas (Tabela 2). Acredita-se 
que o estudo de caso foi o procedimento mais utilizado por causa de sua característica de ser um estudo profundo e exaustivo e com um ou poucos objetos, de forma que possibilita seu amplo e detalhado conhecimento, conforme explicado por Gil (2008).

Tabela 2 Procedimentos técnicos utilizados nas 144 pesquisas

\begin{tabular}{lll}
\hline & \multicolumn{1}{c}{ Tipo } & Quantidade \\
\hline Estudo & Simples & 77 \\
\cline { 2 - 3 } de caso & Múltiplo & 16 \\
\hline Relato de experiência & 14 \\
\hline Pesquisa-ação & 10 \\
\hline Levantamento bibliográfico & 8 \\
\hline Pesquisa documental & 7 \\
\hline Estudo de campo & 5 \\
\hline Intervenção & 2 \\
\hline Método fenomenológico & 2 \\
\hline Pesquisa experimental & 2 \\
\hline Estudo comparativo & 1 \\
\hline
\end{tabular}

Fonte: Elaborada pelos autores.

Na Tabela 3 estão apresentados os instrumentos de coletas de dados escolhidos pelos 144 pesquisadores.

Tabela 3 Instrumentos de coleta de dados usados nas 144 pesquisas

\begin{tabular}{llc} 
& \multicolumn{1}{l}{ Tipo } & Quantidade \\
\hline \multirow{2}{*}{ Observação } & Não participativa & 53 \\
\cline { 2 - 3 } & Participativa & 40 \\
\hline \multirow{2}{*}{ Entrevista } & Estruturadas & 11 \\
\cline { 2 - 3 } & Semiestruturadas & 5 \\
\cline { 2 - 3 } & Anamnese & 1 \\
\hline
\end{tabular}




\begin{tabular}{|c|c|}
\hline Tipo & Quantidade \\
\hline Questionário & 21 \\
\hline Gravações de vídeos & 15 \\
\hline Levantamento de documentos & 8 \\
\hline Aplicação de testes & 6 \\
\hline Diário de campo & 5 \\
\hline Sessões de follow-up & 4 \\
\hline Fotografias & 3 \\
\hline Uso de protocolos de atividades & 3 \\
\hline Inventário & 1 \\
\hline $\begin{array}{l}\text { Uso de técnica de associação livre e dos procedimentos de } \\
\text { classificação múltipla }\end{array}$ & 1 \\
\hline Levantamento de bibliografias & 1 \\
\hline Técnica de grupo focal & 1 \\
\hline
\end{tabular}

Fonte: Elaborada pelos autores.

Percebeu-se, durante a procura por esses instrumentos, que várias pesquisas utilizaram mais de um instrumento para coletar seus dados, como forma de complementação para obter dados mais fidedignos. Verificou-se que a maioria dos instrumentos de coleta de dados são os empregados nas pesquisas qualitativas, o que está coerente com os procedimentos técnicos da maioria das 139 pesquisas analisadas. Observou-se ainda que alguns instrumentos escolhidos geralmente são usados na ciência social, tal como o diário de campo. Eles já estão sendo utilizados por outras áreas, como nas ciências humanas, principal área de estudo das 144 pesquisas analisadas. Chamou a atenção, em uma pesquisa, o uso da entrevista do tipo anamnese, que normalmente é adotada na área da saúde.

Por fim, vale ressaltar que as análises dos dados das 139 pesquisas que adotaram a abordagem qualitativa orientaram-se pelos pressupostos da análise de conteúdo e pela análise do discurso do sujeito coletivo, que são formas de analisar dados qualitativos, de acordo com Mayring (2002). Já os pesquisadores que fizeram uma abordagem quantitativa refletiram sobre seus dados 
por meio do método de comparação constante (sobreposição das fases de coleta e análise dos dados ao longo da pesquisa).

\section{Lócus das pesquisas e caracterização dos alunos}

Todas as pesquisas foram desenvolvidas em escolas regulares da educação básica (englobando a educação infantil e os ensinos fundamental e médio), critério adotado neste estudo para a seleção das dissertações e teses a serem analisadas. Percebeu-se que a maioria das pesquisas foi realizada com alunos com TEA que frequentavam o ensino fundamental $(63,75 \%)$, seguidas pelas pesquisas com os alunos da educação infantil (30\%) e do ensino médio $(6,25 \%)$. Esse resultado, em que o número de matrículas do ensino fundamental foi maior em relação às demais etapas do ensino da educação básica, corroborou os dados apresentados por Santos e Elias (2018) referentes a uma pesquisa sobre a distribuição de matrículas dos alunos com TEA por etapas de ensino.

Verificou-se, também, que todos os alunos presentes nessas pesquisas possuíam laudo comprovando o TEA e que 31\% deles participavam de algum tipo de AEE fora da escola regular, como complemento da sua formação acadêmica. Entretanto, as pesquisas não mencionaram quais eram esses atendimentos e não abordaram a influência ou consequência deles na aprendizagem do aluno na escola regular. Observou-se ainda que o fenótipo desses alunos variava dentro da gama de manifestações definidas pela décima edição da Classificação Internacional de Doenças (CID-10), ou seja, eles tramitavam entre o autismo leve, o moderado e o severo.

Constatou-se também que $77 \%$ desses alunos eram do sexo masculino e $23 \%$ do sexo feminino. Essa predominância do sexo masculino também é observada em dados similares do Censo Escolar de 2016 do Inep: 76,2\% das matrículas de alunos com TEA são do sexo masculino e $23,8 \%$ do sexo feminino.

\section{Os resultados encontrados pelos autores das dissertações e teses}

Todos os autores das 144 pesquisas concordam que os alunos com autismo têm uma forma diferente de ver o mundo e de interagir com ele, e que a maneira como os professores interagem com esses alunos nem sempre é diferenciada. Além disso, ao longo da leitura dessas pesquisas, pôde-se observar a existência de casos de sucessos (neste artigo, denominados fatores positivos) e de fracassos (neste artigo, denominados fatores negativos) no que se refere à inserção e à aprendizagem de alunos com TEA em escolas regulares. Esses fatores estão apresentados no Quadro 2. 


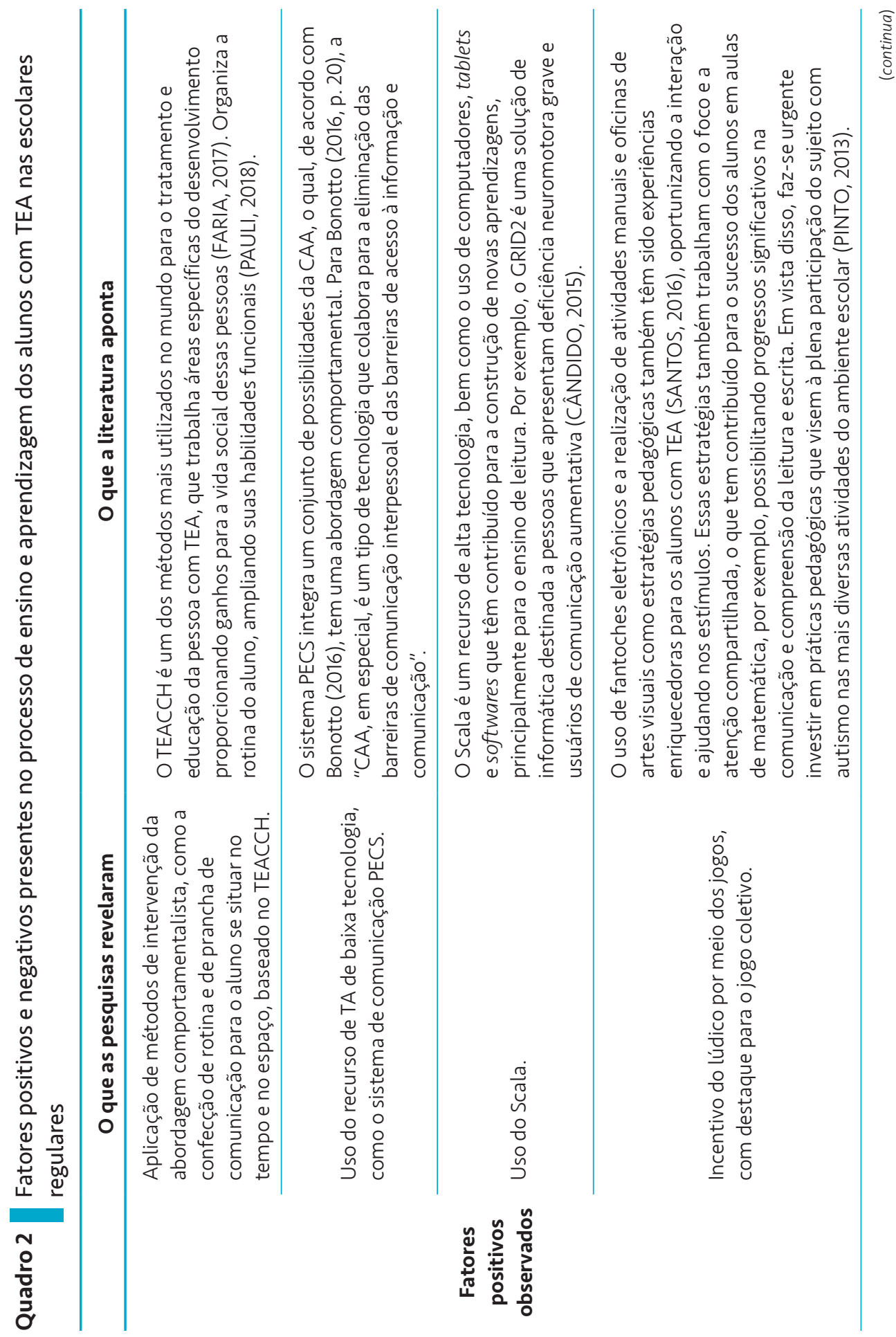




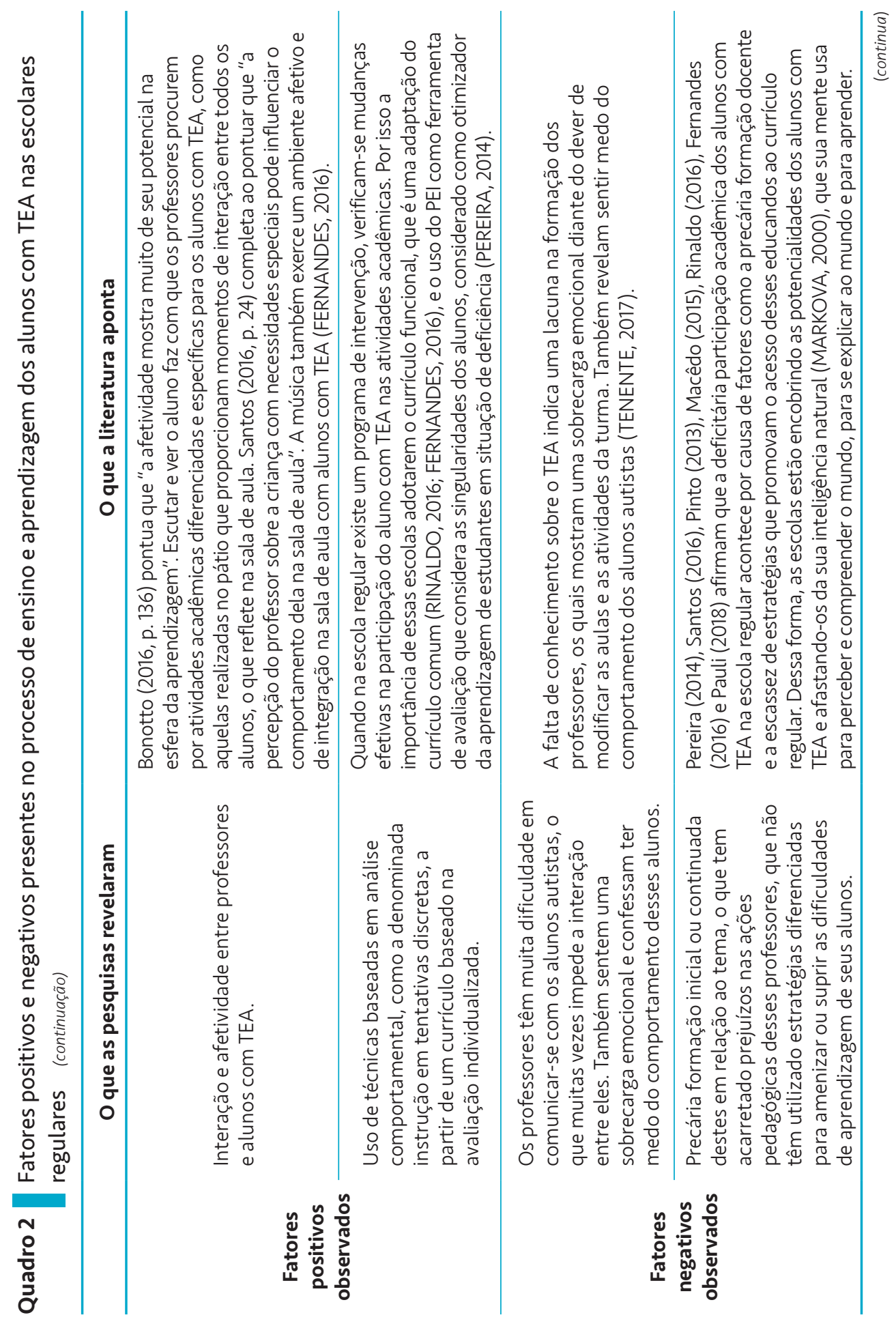




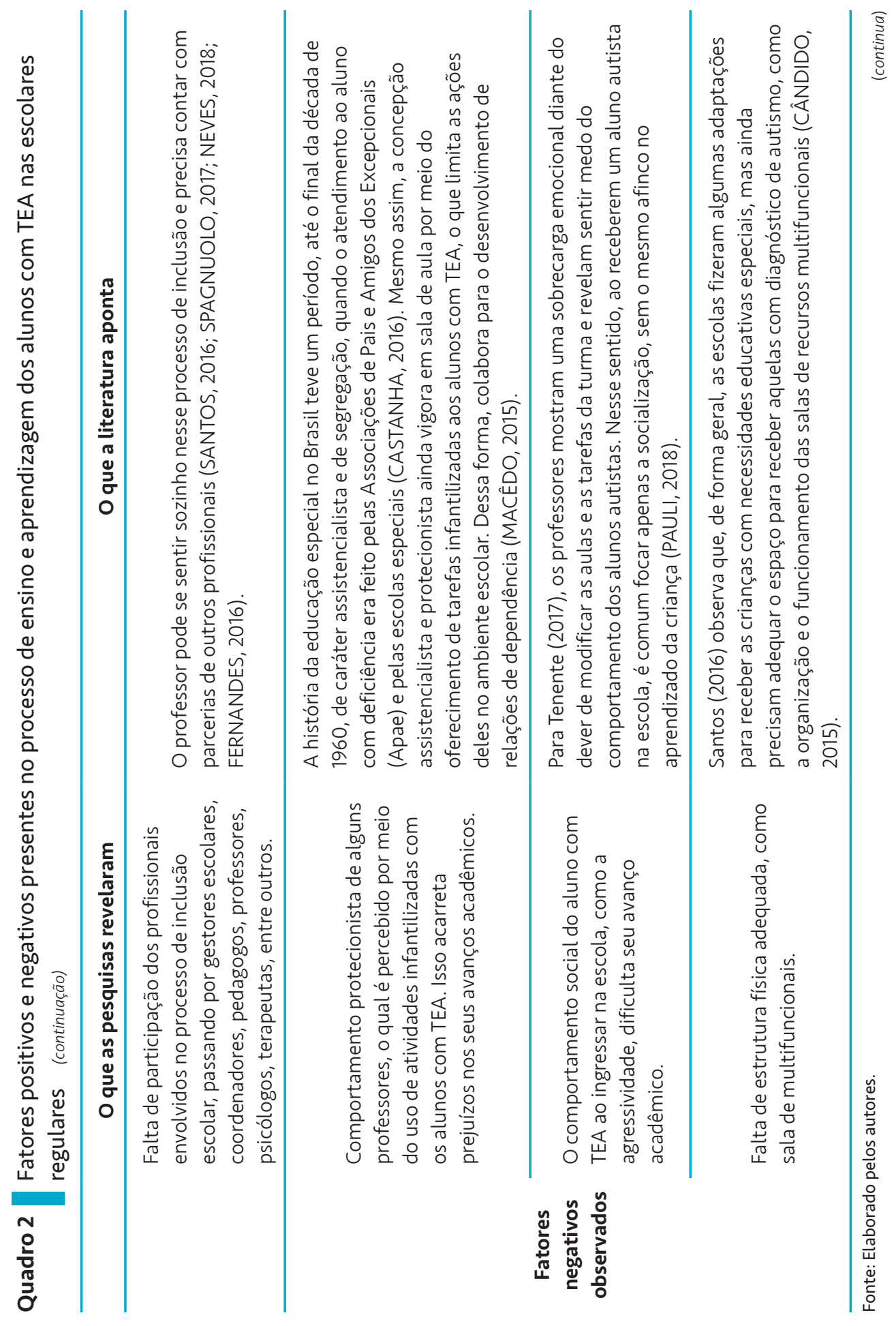


Os fatores apresentados no Quadro 2 representam, portanto, as sínteses das conclusões dos autores deste artigo em relação às 144 pesquisas analisadas. Sobre os fatores negativos, pode-se dizer que eles foram os responsáveis pelo fato de a inclusão dos alunos com TEA ainda não ser uma realidade, apesar da existência de legislações que deveriam favorecer essa inclusão, que ainda se aproxima da segregação. Outro fator que despertou a atenção foi a necessidade de capacitar os professores, seja na formação inicial ou continuada, seja para melhorar suas práticas pedagógicas e incluir os alunos autistas.

No entanto, também existem fatores positivos que proporcionaram uma melhora no comportamento e nos avanços acadêmicos dos alunos com TEA que estudam na escola regular.

\section{DISCUSSÃO}

Com base nos resultados apresentados, foi possível esquematizar um diagrama de causa e efeito das principais dificuldades apresentadas nas 144 pesquisas sobre o processo de ensino e aprendizagem dos alunos com TEA na escola regular (Figura 1). Durante a leitura dessas pesquisas, pôde-se perceber que as causas tinham origens intrínsecas e extrínsecas. As causas intrínsecas estão relacionadas com as características individuais que cada aluno já possuía ao ingressar na escola. Já as causas extrínsecas são devidas ao ambiente escolar.

Figura 1 Diagrama de causa e efeito das principais dificuldades no processo de ensino e aprendizagem dos alunos com TEA

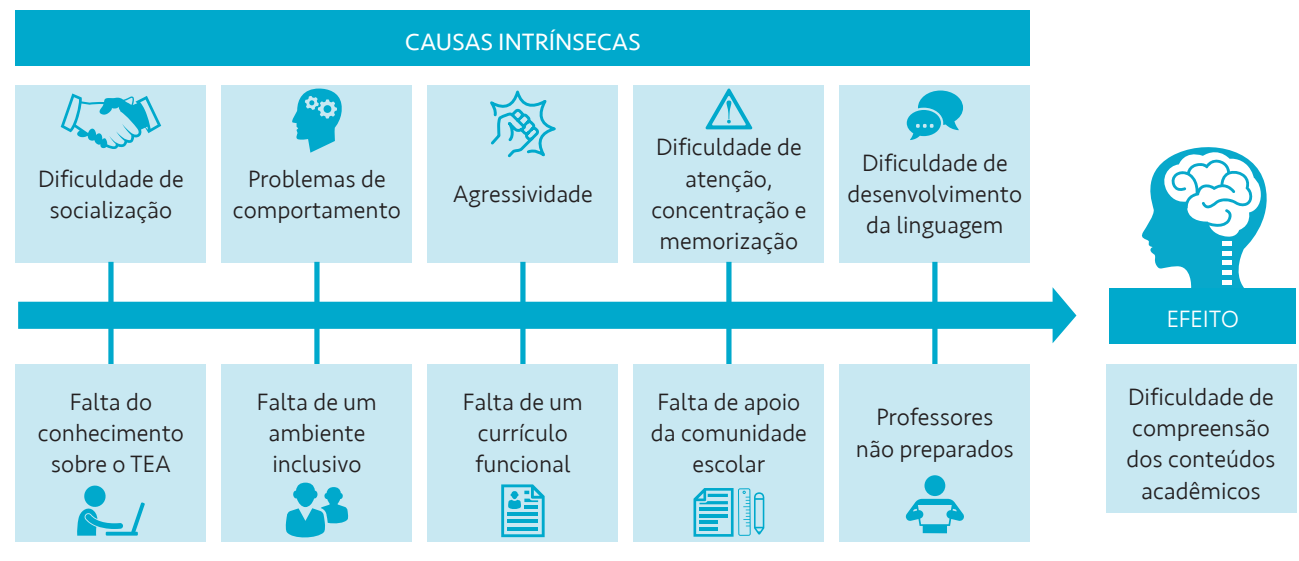

Fonte: Elaborada pelos autores. 
À vista disso, pode-se afirmar que são muitas as causas para a dificuldade acadêmica dos alunos com TEA. Observa-se também que as causas extrínsecas reforçam as causas intrínsecas, e juntas contribuem para o efeito (dificuldade de compreensão dos conteúdos acadêmicos). Pode-se verificar também que a relação causa e efeito mostra a existência de uma conexão que não é acidental, cuja solução não é atacar o efeito, mas, sim, atacar as causas, corrigindo os problemas em sua origem. E é exatamente isso que os 144 pesquisadores procuraram fazer ao apontarem os problemas e as possíveis soluções para incluir o aluno com TEA nas escolas regulares. Então, os autores deste artigo, com base em Silva (2018), Spagnuolo (2017), Santos (2016), Pauli (2018), Fernandes (2016), Rinaldo (2016), Macêdo (2015) e Cândido (2015), destacam dez pontos que precisam ser atacados para diminuir as dificuldades encontradas no processo de ensino e aprendizagem pelos alunos com TEA:

1. Incluir o educador voluntário nas escolas regulares.

2. Intensificar o uso das TA e dos métodos de intervenção com atividades que proporcionem o convívio de forma ampla.

3. Incluir terapeuta escolar para auxiliar no processo de inclusão e de subjetivação.

4. Incluir profissionais de apoio ao professor dentro da sala de aula.

5. Adaptar os conteúdos e desenvolver atividades e avaliações que considerem as habilidades e características de cada aluno.

6. Iniciar o processo de escolarização dos alunos com TEA na escola regular, na primeira etapa da educação básica, para que eles comecem mais cedo seu processo de socialização, preparando-os para as futuras etapas, que exigirão mais atividades acadêmicas.

7. Colocar em prática as leis de inclusão.

8. Investir na formação do docente no que se refere à educação especial, a fim de que os futuros professores possam estar preparados para atuar com os alunos com TEA.

9. Desenvolver o currículo funcional.

10. Usar estratégias pedagógicas que promovam o acesso dos alunos com TEA ao currículo regular.

Somam-se a essas sugestões aquelas apresentadas no Quadro 1, no qual estão listadas as estratégias pedagógicas convencionais, os métodos de intervenções e as TA, dialogando com a neurociência, para serem utilizadas com 
os alunos com TEA. Acredita-se, portanto, que esse caminho poderá levar à inclusão, posto que é discutível se os direitos dos alunos com TEA nas escolas regulares estão sendo garantidos, no sentido de tornar a escola regular e suas salas de aula mais integradoras e includentes, e não segregadoras e assistencialistas. Porém, sabe-se que esse caminho é longo e, como alerta Castanha (2016, p. 117), "os primeiros passos foram dados, mas a luta pela inclusão real, integral, que leva à emancipação das pessoas com deficiência, entre elas os autistas, ainda requer muito de nossas energias para debater, questionar e cobrar".

\section{CONSIDERAÇÕES FINAIS}

A questão que originou este estudo - "A escola regular está pronta para receber em suas salas de aula o aluno com TEA?" - tem como resposta que ainda não. Embora o número de alunos com TEA em escolas regulares tenha crescido a cada ano, este estudo revelou que a inclusão e a aprendizagem ainda são desafios a serem superados. Destarte, exige-se o conhecimento das peculiaridades do modo de funcionamento desses alunos, e fazer a matrícula apenas não significa incluir. Pôde-se chegar a esse resultado ao finalizar a revisão nas produções de pesquisas apresentadas nos programas de pós-graduação em nível de mestrado e doutorado, no Brasil, sobre o processo de ensino e aprendizagem de alunos com TEA em escolas regulares, que foi o objetivo deste artigo, o qual foi alcançado.

Pelos olhares dos 144 pesquisadores (autores das dissertações e teses), pôde-se concluir que a maior necessidade para incluir o aluno com TEA nas escolas regulares é o investimento na formação inicial e continuada dos professores das salas de aula das escolas regulares, que precisam mudar sua prática docente para interagir com esses alunos, como também alerta Santos (2016). Assim, os professores estarão mais seguros e aptos para fazer as melhores escolhas pedagógicas, como atividades diversificadas ou adaptadas, TA, CAA e métodos de intervenção. Dessa forma, a escola regular será um espaço de promoção não apenas para a socialização, mas também para a aquisição das capacidades cognitivas que ajudarão no desenvolvimento acadêmico do aluno com essa síndrome.

Além disso, um instrumento útil para ajudar no processo de inclusão dos alunos com TEA é o PEI, que, conforme as pesquisas mostraram, apresenta um potencial adaptativo coerente com a diversidade da síndrome, definido como 
um recurso pedagógico, centrado no aluno, elaborado colaborativamente e que estabelece metas acadêmicas e funcionais aos educandos com deficiência, conforme Pereira (2014).

Aqui vale enfatizar que essa inclusão dos alunos com TEA na escola regular promoverá a aprendizagem de todos os envolvidos, pois é preciso unir para incluir. Entretanto, pode-se verificar, pelos relatos dos pesquisadores, que ainda é raro a escola que possui um serviço de apoio aos professores no trabalho com os alunos autistas, cabendo ao docente a busca por informações, em seu tempo livre, para tentar algum tipo de planejamento diferenciando para suas aulas. Dessa forma, "os docentes mostram uma sobrecarga emocional diante do dever de modificar as aulas e as tarefas da turma e revelam sentir medo do comportamento dos alunos autistas" (TENENTE, 2017, p. 8). Tenente (2017, p. 8) ainda complementa que os docentes "parecem experimentar um fracasso pessoal quando não veem mudanças positivas nos estudantes - e sentem orgulho quando notam algum tipo de conquista".

Sobre a perspectiva das legislações pertinentes ao tema, perceberam-se avanços importantes, principalmente por permitirem a desvinculação da proposta de uma educação para pessoas com deficiência que deve ser realizada apenas em escolas especiais. Todavia, é preciso lembrar que "ao incluir esses sujeitos na educação regular é imprescindível rever as práticas pedagógicas para o atendimento às necessidades desses alunos" (SILVA; COSTA; GROSSI, 2017, p. 6). A escola regular ainda tem muito a fazer, desde a adaptação de suas estruturas físicas e pedagógicas até o investimento na formação continuada do seu corpo docente. Esse, sim, será um caminho para que ela possa atender de forma inclusiva.

Por fim, sobre as dificuldades na realização deste artigo, vale salientar uma preocupação que os autores tiveram no início deste estudo: a mudança na classificação dos transtornos mentais, o DSM. Em 2013, foi publicada uma nova classificação: o DSM-5. Os autores do artigo ficaram receosos com possíveis impactos nos seus estudos, especificamente com a questão de novas nomenclaturas, o que poderia dificultar a coleta, comparação e análise dos dados, posto que, das 144 pesquisas analisadas, 50 foram desenvolvidas no período de vigência da versão anterior (DSM-IV), e 94, após a publicação do DSM-5. Porém, ao longo do estudo, percebeu-se que as mudanças na nova classificação não trouxeram prejuízos para as análises das 144 pesquisas. 


\title{
The process of teaching and learning of students with ASD in regular schools: a review of theses and dissertations
}

\begin{abstract}
This article aimed to review master's and doctoral dissertations that analyzed the teaching and learning process of students with autism spectrum disorder (ASD) in regular schools. Thus, a documentary research was done, in which documents from the bank of theses and dissertations portal of the Brazilian Institute of Information in Science and Technology (Ibict) were used. The study corpus consisted of 772 surveys. However, after a preliminary reading, 144 surveys were selected for analysis, since 419 were not focused on the teaching and learning process in regular schools and 209 appeared repeated in the search, which was carried out at the end of the 1st semester of 2019. It is worth noting that there was no time cut. The results revealed that, although the legislation pertinent to the topic has provided some guarantees and the number of students with ASD in regular schools has grown, the inclusion and learning of these students is not yet a reality, as inclusion does not mean just enrolling. The regular school still has a lot to do, such as, for example, the adaptation of its physical structures, changes in its pedagogical actions, use of assistive technologies and intervention methods, and the inclusion of functional curricula. It is also necessary to invest in the continuing education of teachers, given that their initial training has not prepared them to deal with students with ASD.
\end{abstract}

\section{Keywords}

Autism spectrum disorders. Students with ASD. Special education. Teaching and learning process. Inclusion.

\section{El proceso de enseñanza y aprendizaje de estudiantes con TEA en escuelas regulares: una revisión de tesis y disertaciones}

\section{Resumen}

Este artículo tuvo como objetivo revisar disertaciones de maestría y doctorado que analizaron el proceso de enseñanza y aprendizaje de los estudiantes con trastorno del espectro autista (TEA) en las escuelas regulares. Así, se realizó una investigación documental, en la cual se utilizaron documentos del banco de tesis y portal de disertaciones del Instituto Brasileño de 
Información en Ciencia y Tecnología (Ibict). El corpus de estudio consistió en 772 encuestas. Sin embargo, después de una lectura preliminar, se seleccionaron 144 encuestas para su análisis, ya que 419 no se centraron en el proceso de enseñanza y aprendizaje en las escuelas regulares y 209 aparecieron repetidas en la búsqueda, que se realizó al final del primer semestre de 2019. Vale la pena señalar que no hubo un corte de tiempo. Los resultados revelaron que, aunque la legislación pertinente al tema ha proporcionado algunas garantías y el número de estudiantes con TEA en las escuelas regulares ha aumentados, la inclusión y el aprendizaje de estos estudiantes aún no es una realidad, ya que la inclusión no significa solo matricularse. La escuela regular todavía tiene mucho que hacer, como, por ejemplo, la adaptación de sus estructuras físicas, los cambios en sus acciones pedagógicas, el uso de tecnologías de asistencia y métodos de intervención, y la inclusión de planes de estudio funcionales. También es necesario invertir en la educación continua de los docentes, dado que su capacitación inicial no los ha preparado para tratar con estudiantes con TEA.

\section{Palabras clave}

Trastorno del espectro autista. Estudiantes con TEA. Educacion special. Proceso de enseñanza y aprendizaje. Inclusión.

\section{REFERÊNCIAS}

AMERICAN PSYCHIATRIC ASSOCIATION. Manual diagnóstico e estatístico de transtornos mentais: DSM-IV-TR. Porto Alegre: Artmed, 2002.

AMERICAN PSYCHIATRIC ASSOCIATION. Manual diagnóstico e estatístico de transtornos mentais: DSM-5. Porto Alegre: Artmed, 2014.

BARTOSZECK, A. B.; GROSSI, M. G. R. A neurociência do autismo. In: BORGES, A. A. P.; NOGUEIRA, M. L. M. (org.). O aluno com autismo na escola. Campinas: Mercado das Letras, 2018. p. 35-63.

BONOTTO, R. C. de S. Uso da comunicação alternativa no autismo: um estudo sobre a mediação com baixa e alta tecnologia. 2016. $181 \mathrm{f}$. Tese (Doutorado em Informática na Educação) - Universidade Federal do Rio Grande do Sul, Porto Alegre, 2016.

BRASIL. Constituição da República Federativa do Brasil. Brasília, DF: Senado Federal, 1988.

BRASIL. Ministério da Educação. Lei no 9.394, de 20 de dezembro de 1996. Estabelece as diretrizes e bases da educação nacional. Diário Oficial da República Federativa do Brasil, Brasília, DF, 20 dez. 1996. Disponível em: http://www.planalto.gov.br/ccivil_03/leis/19394.htm. Acesso em: 25 ago. 2019. 
BRASIL. Casa Civil. Decreto no 3.298, de 20 de dezembro de 1999. Regulamenta a Lei $\mathrm{n}^{\circ}$ 7.853, de 24 de outubro de 1989, dispõe sobre a Política Nacional para a Integração da Pessoa Portadora de Deficiência, consolida as normas de proteção, e dá outras providências. Disponível em: http://www.planalto.gov.br/ccivil_03/decreto/d3298.htm. Acesso em: 10 ago. 2019.

BRASIL. Casa Civil. Lei no 12.764, de 27 de dezembro de 2012. Institui a Política Nacional de Proteção dos Direitos da Pessoa com Transtorno do Espectro Autista; e altera o $\S 3^{\circ}$ do art. 98 da Lei $n^{\circ} 8.112$, de 11 de dezembro de 1990. Disponível em: http://www.planalto.gov.br/ccivil_03/_ato2011-2014/2012/lei/112764.htm. Acesso em: 10 jun. 2019.

BRASIL. Secretaria da Saúde. Autismo. 2019. Disponível em: http://www.saude. pr.gov.br/modules/conteudo/conteudo.php?conteudo=3345. Acesso em: 14 jun. 2019.

CÂNDIDO, F. R. Tecnologias assistivas e inclusão escolar: o uso do software GRID2 no atendimento educacional especializado a estudante com autismo em escola pública do Distrito Federal. 2015. 238 f. Dissertação (Mestrado em Educação) - Universidade de Brasília, Brasília, 2015.

CASTANHA, J. G. Z. A trajetória do autismo na educação: da criação das associações à regulamentação da política de proteção (1983-2014). 2016. 130 f. Dissertação (Mestrado em Educação) - Universidade Estadual do Oeste do Paraná, Cascavel, 2016.

COORDENAÇÃO DE APERFEIÇOAMENTO DE PESSOAL DE NÍVEL SUPERIOR. GeoCapes Visão Analítica. 2018. Disponível em: https://geocapes.capes.gov.br/geocapes/. Acesso em: 21 ago. 2019.

EISSA, N. et al. Current enlightenment about etiology and pharmacological treatment of autism spectrum disorder. Frontiers in Neuroscience, v. 12, n. 304, p. 1-26, 2018. DOI: 10.3389/fnins.2018.00304.

FARIAS, E. B. Validação empírica de uma abordagem para alfabetização de autistas utilizando aplicativos para dispositivos móveis. 2017. 212 f. Dissertação (Mestrado em Informática) - Universidade Federal de Alagoas, Maceió, 2017.

FERNANDES, A. L. M. O papel da música no currículo funcional do ensino de ciências para alunos com autismo: formação continuada. 2016. 83 f. Dissertação (Mestrado Profissional em Ensino de Ciências) - Universidade Federal de Itajubá, Itajubá, 2016.

GIL, A. C. Como elaborar projetos de pesquisa. 4. ed. São Paulo: Atlas, 2008.

GROSSI, M. G. R.; LOPES, A. M.; COUTO, P. A. Neurociência na formação de professores: um estudo da realidade brasileira. Revista da Faeeba - Educação e Contemporaneidade, Salvador, v. 23, n. 41, p. 27-40, 2014. DOI:10.21879/faeeba2358-0194.2014. v23.n41.p\%25p 
GROSSI, M. G. R.; OLIVEIRA, E. E.; AGUIAR, F. A. A neurociência na formação inicial de professores: uma investigação científica. Ensino Em Re-Vista, Uberlândia, v. 26, n. 3, p. 871-895, 2019. DOI:10.14393/ER-v26n3a2019-12

GÜNTHER, H. Pesquisa qualitativa versus pesquisa quantitativa: esta é a questão? Psicologia: Teoria e Pesquisa, v. 22, n. 2, p. 201-210, 2006. DOI: 10.1590/S010237722006000200010

HALLMAYER, J. et al. Genetic heritability and shared environmental factors among twin pairs with autism. Archives of General Psychiatry, v. 68, n. 11, p. 1095-1102, 2011. DOI: 10.1001/archgenpsychiatry.2011.76.

INSTITUTO NACIONAL DE ESTUDOS E PESQUISAS EDUCACIONAIS. Microdados do Censo Escolar 2016. Disponível em: http://portal.inep.gov.br/web/guest/censo-escolar. Acesso em: 29 jul. 2019.

INSTITUTO NACIONAL DE ESTUDOS E PESQUISAS EDUCACIONAIS. Censo Escolar 2018. Disponível em: http://portal.inep.gov.br/web/guest/censo-escolar. Acesso em: 29 jul. 2019.

MACÊDO, C. R. de. A criança com transtorno do espectro autista (TEA) e o professor: uma proposta de intervenção baseada na experiência de aprendizagem mediada (EAM). 2015. 163 f. Dissertação (Mestrado em Educação) - Universidade Federal do Rio Grande do Norte, Natal, 2015.

MARKOVA, D. O natural e ser inteligente: padrões básicos de aprendizagem a serviço da criatividade e educação. São Paulo: Summus, 2000.

MAYRING, P. Einführung in die qualitative Sozialforschung. 5. ed. Weinheim: Beltz, 2002.

MIGUÉIS, A. et al. A importância das palavras-chave dos artigos científicos das áreas das ciências farmacêuticas, depositados no estudo geral: estudo comparativo com os termos atribuídos na Medline. InCID: Revista de Ciência da Informação e Documentação, Ribeirão Preto, v. 4, n. 2, p. 112-125, 2013. DOI: 10.11606/issn.2178-2075. v4i2p112-125

NEVES, P. F. de A. C. Descortinando os propósitos da educação para as crianças com transtorno do espectro autista: em cena os serviços de apoio. 2018. 135 f. Dissertação (Mestrado em Educação) - Universidade Federal de Goiás, Catalão, 2018.

ORGANIZAÇÃO DAS NAÇÕES UNIDAS. Rejeitar pessoas com autismo é um desperdício de potencial humano. 2016. Disponível em: https://nacoesunidas.org/rejeitar-pessoas-com-autismo-e-um-desperdicio-de-potencial-humano-destacam-representantes-da-onu/. Acesso em: 10 ago. 2019.

PARK, H. R. et al. A short review on the current understanding of autism spectrum disorders. Experimental Neurobiology, v. 25, n. 1, p. 1-13, 2016. DOI: 10.5607/en.2016.25.1.1 
PAULI, P. A. C. de. A integração das tecnologias ao currículo inclusivo de crianças com TEA: um estudo de caso. 2018. 201 f. Dissertação (Mestrado em Educação) - Pontifícia Universidade Católica de São Paulo, São Paulo, 2018.

PEREIRA, D. M. Análise dos efeitos de um plano educacional individualizado no desenvolvimento acadêmico e funcional de um aluno com transtorno do espectro do autismo. 2014. 181 f. Dissertação (Mestrado em Educação) - Universidade Federal do Rio Grande do Norte, Natal, 2014.

PINTO, S. da S. Práticas pedagógicas e o sujeito com autismo: um estudo de caso fenomenológico no ensino comum. 2013. 175 f. Dissertação (Mestrado em Educação) Universidade Federal do Espírito Santos, Vitória, 2013.

RINALDO, S. C. de O. Processo educacional de crianças com transtorno do espectro autista na educação infantil: interconexões entre contextos. 2016. 142 f. Dissertação (Mestrado em Educação) - Universidade Estadual Paulista "Júlio de Mesquita Filho", Araraquara, 2016.

SANTOS, A. de A. Inclusão escolar de crianças diagnosticadas com transtorno do espectro autista: significados e práticas. 2016. 131 f. Dissertação (Mestrado em Psicologia do Desenvolvimento) - Universidade Federal da Bahia, Salvador, 2016.

SANTOS, V.; ELIAS, N. C. Caracterização das matrículas dos alunos com transtorno do espectro do autismo por regiões brasileiras. Revista Brasileira de Educação Especial, Marília, v. 24, n. 4, p. 465-482, 2018. DOI: 10.1590/s1413-65382418000500001

SILVA, G. E. de O. O papel do educador social voluntário no processo de inclusão de estudantes com transtorno do espectro autista. 2018. 94 f. Dissertação (Mestrado em Educação) - Universidade Católica de Brasília, Brasília, 2018.

SILVA, L. C.; COSTA, M. A. B.; GROSSI, M. G. R. Tecnologias assistivas nos ambientes virtuais de aprendizagem dos cursos técnicos a distância do Cefet-MG: quais as possibilidades? Cadernos de Pós-Graduação, São Paulo, v. 16, n. 2, p. 121-144, 2017. DOI: 10.5585/cpg.v16n2.7584

SPAGNUOLO, L. S. Acompanhamento terapêutico na escola: entre o educar e o analisar. 2017. 187 f. Dissertação (Mestrado em Educação) - Universidade de São Paulo, São Paulo, 2017.

TENENTE, L. B. A visão da escola sobre a inclusão de crianças com autismo. 2017. 190f. Dissertação (Mestrado em Linguística Aplicada e Estudos da Linguagem) - Pontifícia Universidade Católica de São Paulo, São Paulo, 2017.

VIANA, A. F. Dança e autismo, espaços de encontro. 2015. 436 f. Tese (Doutorado em Educação) - Universidade Estadual de Campinas, Campinas, SP, 2015. 